\title{
Nutri-Score: A Public Health Tool to Improve Eating Habits in Portugal
}

\author{
Nutri-Score: Uma Ferramenta de Saúde Pública para \\ Melhorar os Hábitos Alimentares da População Portuguesa
}

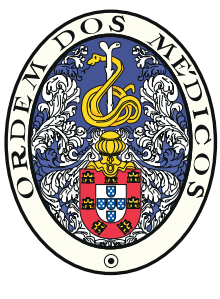

Francisco GOIANA-DA-SILVAه্凶${ }^{1,2}$, David CRUZ-E-SILVA ${ }^{3}$, Maria João GREGÓRIO ${ }^{4,5,6}$, Alexandre Morais NUNES ${ }^{7}$, Conceição CALHAU ${ }^{8,9}$, Serge HERCBERG ${ }^{10,11}$, Ana RITO ${ }^{12}$, Alexandra BENTO ${ }^{13}$, Diogo CRUZ $^{4}$, Fernando ALMEIDA ${ }^{12}$, Ara DARZI'14, Fernando ARAÚJO'15,16

Acta Med Port 2019 Mar;32(3):175-178 - https://doi.org/10.20344/amp.11627

Keywords: Consumer Behavior; Feeding Behavior; Food Labeling; Portugal; Public Health

Palavras-chave: Comportamento Alimentar; Comportamento do Consumidor; Portugal; Rotulagem de Alimentos; Saúde Pública

\section{INTRODUCTION}

Non-communicable diseases (NCDs) are associated with avoidable behavioural risk factors and several opportunities for intervention - such as unhealthy diets, lack of physical activity, tobacco use and excessive alcohol consumption ${ }^{1}$ - are available.

Unhealthy diets are among the most contributable risk factors to the decrease in healthy life years among the Portuguese population $(15.8 \%)$. Furthermore, dietary habits are important determinants for NCDs, representing $86 \%$ of the burden of disease on the Portuguese National Healthcare System (NHS). ${ }^{1}$

Integrated strategies on prevention of NCDs which include the promotion of healthy lifestyles, including diet, and disease prevention measures must be a priority. In this context, the Portuguese Ministry of Health published the Integrated Strategy for the Promotion of Healthy Eating (Estratégia Integrada para a Promoção da Alimentação Saudável - EIPAS). ${ }^{2}$

A recent study showed that $40 \%$ of all people surveyed in Portugal do not understand nutritional information on food labels. ${ }^{3}$ With this in mind, one of the strategic axes of EIPAS is to "Improve the quality and accessibility of the information available to consumers". In order to pursue this strategic objective, several measures have been mapped out, including promoting the usage of front-of-pack (FOP) labelling. ${ }^{2,4}$

guidance for the implementation of FOP labelling systems. ${ }^{4}$ As such, the following sections present the growing evidence on the impact of the Nutri-Score labelling scheme in promoting healthier eating behaviours and informs health professionals, as well as decision makers, on the way forward.

\section{FOP nutrition labelling systems}

FOP labelling was initially introduced in the late 1980s and, to date, several countries and companies have adopted it. Endorsement (Key Hole Healthy Choice), nutrient specific interpretative models (Traffic Light System), summary interpretative models (Nutri-Score) and numeric informative models (Guideline Daily Amount System) are among the most popular examples of FOP labelling systems.

Research suggests that several criteria impact the efficacy of FOP labelling systems. These criteria pertain, mostIy, to acceptability, objective comprehension and the impact of the labels' usage on consumers' buying decisions. ${ }^{5}$

\section{Growing evidence that Nutri-Score is a scheme that works for consumers}

Nutri-Score consists of a graphical coloured representation, which also uses letters. The system classifies the nutritional profile of a food product into five mutually exclusive categories. An innovative algorithm based on nutritional criteria, validated scientifically, classifies products between

This article intends to help filling the existing gap in

1. Centre for Health Policy. Institute of Global Health Innovation. Imperial College London. London. United Kingdom.

2. Faculdade de Ciências da Saúde. Universidade da Beira Interior. Covilhã. Portugal.

3. Center for Innovation, Technology and Policy Research, IN+. Instituto Superior Técnico. Universidade de Lisboa. Lisboa. Portugal.

4. Health Directorate-General. Lisboa. Portugal.

5. Faculty of Nutrition and Food Sciences. University of Porto. Porto. Portugal.

6. EpiDoC Unit. Chronic Diseases Research Center (CEDOC). NOVA Medical School. Lisboa. Portugal.

7. Centro de Administração e Políticas Públicas. Instituto Superior de Ciências Sociais e Políticas. Universidade de Lisboa. Lisboa. Portugal.

8. Department of Nutrition and Metabolism. NOVA Medical School. Lisboa. Portugal.

9. Center for Health Technology Services Research (CINTESIS). Porto. Portugal.

10. Equipe de Recherche en Epidémiologie Nutritionnelle (EREN). Inserm, Inra, Cnam. Université Paris 13. Paris. France.

11. Département de Santé Publique. Hôpital Avicenne (AP-HP). Bobigny. France.

12. Instituto Nacional de Saúde Doutor Ricardo Jorge. National Institute of Health. Lisboa. Portugal.

13. Portuguese Order of Nutritionists. Lisboa. Portugal.

14. Department of Surgery and Cancer. Faculty of Medicine. Imperial College London. London. United Kingdom.

15. Faculty of Medicine. Porto University. Porto. Portugal.

16. Serviço de Imuno-hemoterapia. Centro Hospitalar Universitário São João. Porto. Portugal.

$\triangle$ Autor correspondente: Francisco Goiana-da-Silva. franciscogoianasilva@gmail.com

Recebido: 03 de dezembro de 2018 - Aceite: 04 de fevereiro de 2019 | Copyright $\odot$ Ordem dos Médicos 2019 
green (associated to letter A) and red (associated to letter E), as demonstrated in Fig. 1.

Recent studies conducted for the development of the French FOP Nutrition Labelling Systems and that compared Nutri-Score with other FOP nutrition labelling systems, suggested that Nutri-Score is the easiest to understand. It is easily recognized and interpreted regardless of socioeconomic and demographic stratus, especially in comparison with the Traffic Light System. Fig. 1 shows different FOP labelling systems applied to different biscuits and illustrates the previously mentioned findings. All population subgroups, in particular overweight and obese individuals, show posi- tive appraisal towards Nutri-Score in detriment of other FOP labelling systems. ${ }^{6,7}$

Even though many different systems allow consumers to identify products with more adequate nutritional profiles, Nutri-Score shows the strongest evidence towards promoting healthier choices by the consumer, namely among those with unhealthier eating behaviours. ${ }^{8}$ Evidence shows that Nutri-Score helps consumers to effectively classify food products according to their nutritional characteristics, even for individuals without technical knowledge on nutrition. Additionally, communication and marketing initiatives on Nutri-Score result in more nutritional adequate choices by

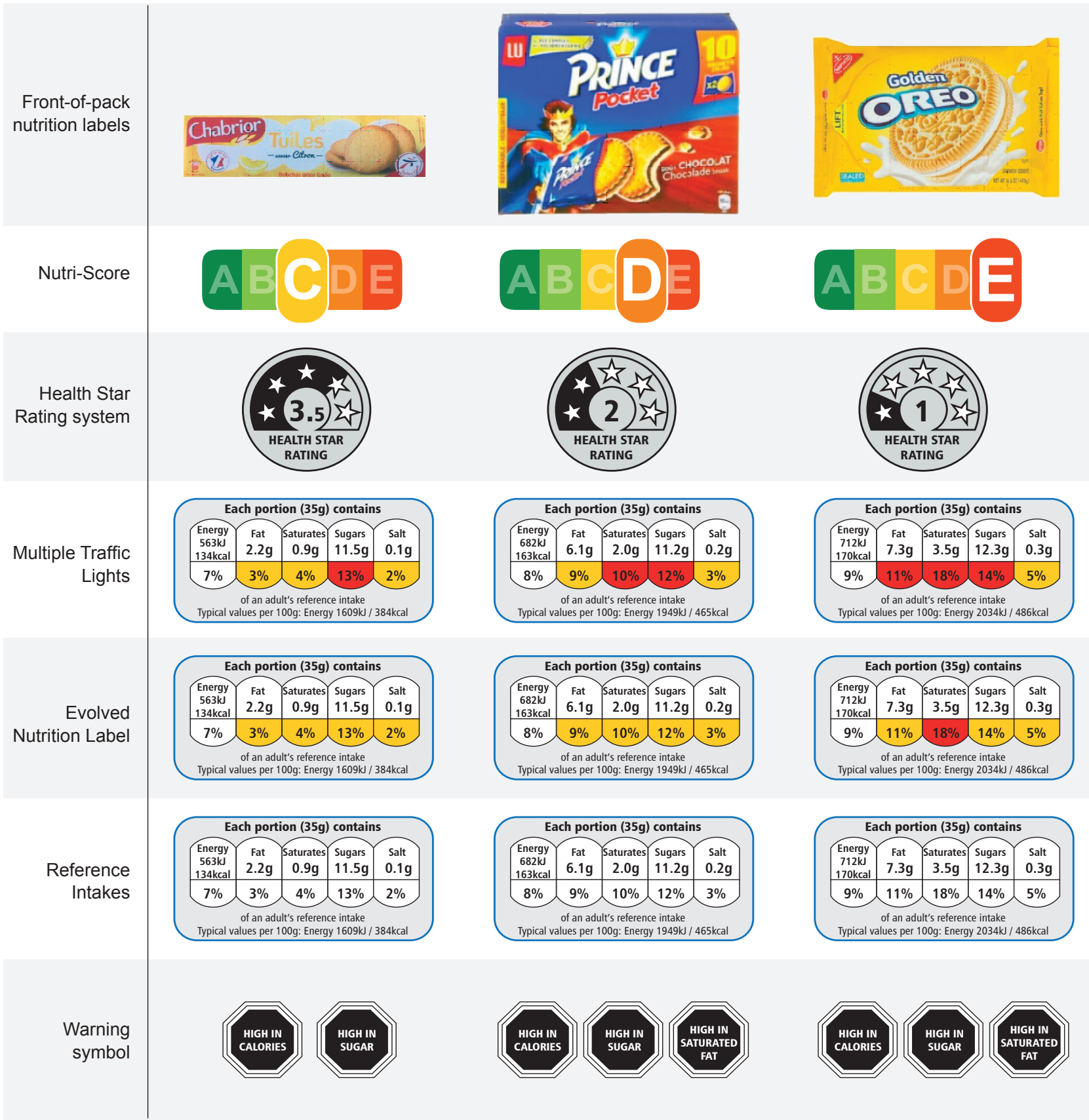

Figure 1 - Different FOP Labelling Systems applied to different biscuits. Detailled explanation of the classification process used by each one of the referred FOPL systems can be found in Kanter et al. ${ }^{9}$

Source: Own authorship 
consumers. This is particularly evident in the sweets, biscuits and cookies food category. ${ }^{8}$

In 2016, a study developed in over 60 supermarkets for a 10-week period, covering around 1298 food products, compared Nutri-Score to other FOP labelling systems. This study concluded that Nutri-Score shows a clear superiority when compared to all other FOP labelling systems and that, unlike other similar systems, never leads to worse choices from a nutritional perspective. In this context it is important to note that Nutri-Score led to an average increase of $4 \%$ in the nutritional quality of food products in shopping baskets. ${ }^{10}$

These results are supported by a qualitative study, carried out in over 20 stores, showing that summary FOP nutrition labelling systems (such as Nutri-Score) are those most effective in guiding consumer shopping and decisionmaking towards food products with better global nutritional profiles. ${ }^{11}$ Moreover, a recent study on 809 individuals under real life shopping environments, and using experimental economy analyses and methodologies, had similar findings, thus reinforcing and supporting the previously mentioned public health benefits of Nutri-Score. ${ }^{12}$

\section{CONCLUSION}

Recent evidence suggests that Nutri-Score significantly improves consumers' ability to better understand nutritional information and make healthier food choices. Nutri-Score has been developed by the French Ministry of Health and defined as the national reference. More than ninety food manufacturers and retailers have followed suit and deployed (or committed to deploying) Nutri-Score on all their products. Furthermore, other Ministries of Health (i.e. Belgium and Spain) have published national recommendation towards adopting Nutri-Score. Nutri-Score also counts with the strong support of European consumers' associations.

In contrast, little progress has been made in Portugal. Lack of decisive action has been promoted by policy and regulatory levers lying outside the health sector, limited collaboration between different governmental areas, and strong opposition by several food manufacturing companies and retail sectors. As a result, several different FOP labelling systems are used at the national level without any type of standardization. The overload of different FOP labelling systems available in the market may confuse consumers instead of improving their decision capacity. Therefore, a national and harmonized FOP labelling system should be implemented. ${ }^{4}$

\section{REFERENCES}

1. Goiana-da-Silva F, Nunes AM, Miraldo M, Bento A, Breda J, Araújo FF. Fiscalidade ao serviço da saúde pública: a experiência na tributação das bebidas açucaradas em Portugal. Acta Med Port. 2018;31:191-5.

2. Goiana-da-Silva F, Cruz-e-Silva D, Gregório MJ, Miraldo M, Darzi $A$, Araújo F. Bringing government sectors together to address noncommunicable diseases - Portugal's interministerial healthy eating strategy. WHO Public Health Panorama. 2018;4;426-34.

3. Gomes S, Nogueira M, Ferreira M, Gregório MJ. Portuguese consumers' attitudes towards food labelling. Copenhagen: WHO; 2017

4. Goiana-da-Silva F, Cruz-e-Silva D, Miraldo M, Calhau C, Bento A, Cruz
In this context, the Portuguese Government, by the hand of the Minister of Health has requested stewardship to the Regional Office for Europe of the World Health Organisation (WHO) regarding the development of an evidence base framework for FOP labelling.

Better evidence on the effectiveness of FOP labelling systems enables the definition of evidence-based national policies and regulations, including a single national coherent nutritional information model.

In response, the WHO produced a report on FOP labelling. Based on the evidence summarized in this report, a number of considerations for adopting or reviewing of labelling policies at the national or regional level were identified. These considerations are key to ensuring that policies achieve the intended health outcomes regarding FOP labelling. These considerations included:

- applying a single FOP labelling system to ensure clear consumer understanding and usage;

- opting for government-led policy development rather than a commercially based system, as consumers perceive the latter as less credible;

- conducting stakeholder engagement and formative research to ensure the selection of the most appropriate policy.

"There are many common traits between French habits and those in Mediterranean countries, not only regarding food, but also in the organization and structure of meals during the day."

The Portuguese population has several similarities with the French population, not only regarding food, but also in the structure and organization of meals. ${ }^{13}$ Building on these, in October 2018, the Regional Director of the WHO officially replied to the Portuguese Government guidance query. It was mentioned that the accumulating evidence from several studies shows that Nutri-Score FOP labelling system meets all the criteria of an effective front of pack labelling system. It is therefore safe to assume that Nutri-Score would be an adequate FOP labelling system to be considered and endorsed by Portugal. The evidence presented suggests that Portugal and other countries shall consider the implementation of this work.

In parallel, it is essential to promote an integrated approach regarding healthy eating promotion policies. In particular, Portugal shall keep the policy innovation trends that characterized a growing intervention of the Ministry of Health in the food sector between 2015 and 2018 as a way to promote Public Health and fight NCDs.

$D$, et al. Front-of-pack labelling policies and the need for guidance Lancet Public Health. 2019;4:e15.

5. Grunert KG, Wills JM. A review of European research on consumer response to nutrition information on food labels. J Public Health. 2007; 15: 385-99.

6. Julia C, Péneau S, Buscail C, Gonzalez R, Touvier M, Hercberg S, et al. Perception of different formats of front-of-pack nutrition labels according to sociodemographic, lifestyle and dietary factors in a French population: cross-sectional study among the NutriNet-Santé cohort participants. BMJ Open. 2017;7: e016108. 
7. Julia C, Hercberg S. Development of a new front-of-pack nutrition labe in France: the five-colour Nutri-Score. Public Health Panor. 2017;3:537820.

8. Ducrot P, Méjean C, Julia C, Kesse-Guyot E, Touvier M, Fezeu LK, et al. Objective understanding of front-of-package nutrition labels among nutritionally at-risk individuals. Nutrients. 2015;7:7106-25.

9. Kanter R, Vanderlee L, Vandevijvere S. Front-of-package nutrition labelling policy: global progress and future directions. Public Health Nutr. 2018;21:1399-408.

10. Fonds français pour l'alimentation. Evaluation ex ante de systèmes d'étiquetage nutritionnel graphique simplifié. Rapport final. Paris: Comité Scientifique de l'étude d'expérimentation; 2017.
11. Les enquetes complementaires (étude quantitative). Evaluation ex ante de systemes d'etiquetage nutritionnel graphique simplfie. Rapport final. Paris: Centre de recherche pour l'étude et l'observation des conditions de vie; 2017.

12. Crosetto $\mathrm{P}$, Muller $\mathrm{L}$, Ruffieux $\mathrm{B}$. Réponses des consommateurs à trois systèmes d'étiquetage nutritionnel face avant. Cah Nutr Diététique. 2016;51: 124-31.

13. Gerber M. Implementing the Mediterranean diet: a French perspective and comparisons with other Mediterranean countries. In: Donato FR, Ornella IS, editors. Mediterranean diet: dietary guidelines and impact on health and disease. New York: Springer; 2016. p. 57-67. 